\title{
Chronic postoperative pain in cardiac surgery
}

\author{
G. Shevtsova', Y. Malenkova', M. Churukanov'1, T. Kuzminova', \\ E. Yakovleva ${ }^{1}$, M. Kachanovskiy ${ }^{1}$ \\ 1I.M. Sechenov First Moscow State Medical University, Moscow, Russia \\ ${ }^{2}$ Petrovsky National Research Centre of Surgery, Moscow, Russia

${ }^{2}$ Petrovsky National Research Centre of Surgery, Moscow, Russia

\section{SECHENOV UNIVERSTTY}

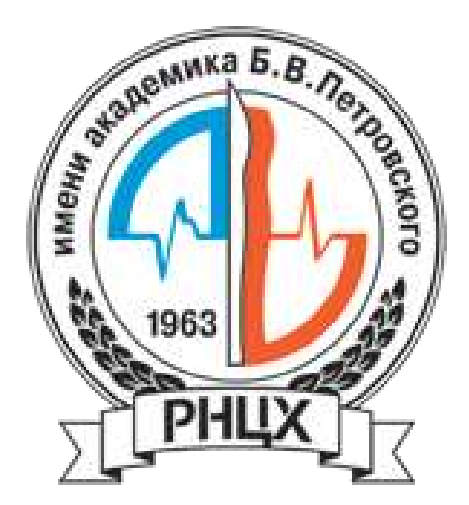

Background and Goal of Study: The number of cardio surgical interventions in the world is increasing every year, leading to a disability and a decrease in the quality of life [1,2]. The incidence of chronic postoperative pain (CPOP) after thoracotomy and sternotomy is $5-65 \%$, indicating severe pain in $10 \%$ of all CPOP patients [3]. This study aims to analyze the incidence of CPOP in cardiac surgery.

Materials and Methods: 107 case histories of patients, operated in Jan. 2015 - Jun. 2016, were retrospectively analyzed. According to the surgery type, all the patients were divided into following groups: bypass surgeries, aorta and cardiac valve replacements, Bentall procedures and combined surgeries (Table 1). We contacted the patients via phone calls in terms of ischemic/anginal pain in the surgical approach area.

Results and Discussion: The majority of participants were men (79,4\%). The mean age was 59,6 years. 37 (34,58\%) respondents reported CPOP: 19 (37.25\%) in the bypass group, 4 (26.7\%) - with aorta and cardiac valve replacement, 8 (33.3\%) - with Bentall procedures, $6(35.3 \%)$ in the group of combined operations (Figure 1). The patient's age, duration of hospitalization and surgery didn't show any statistical significance according to the Mann-Whitney criterion in the development of CPOP.

Conclusion(s):The incidence of CPOP in cardiac surgery is $34.58 \%$ that represents a coincidence with the current world literature data. Considering the importance of CPOP prevention, future studies of its predisposing factors are needed.

\begin{tabular}{|c|c|}
\hline $\mathrm{N}$ & 107 \\
\hline Age & $59.6(24-79)$ \\
\hline $\operatorname{Sex}(F, \%)$ & $22.56 \%$ \\
\hline $\begin{array}{l}\text { Diabetes (yes, \%) } \\
\text { Hypermobility (yes, \%) }\end{array}$ & $\begin{array}{l}9.35 \% \\
3.7 \%\end{array}$ \\
\hline $\begin{array}{l}\text { Surgical type } \\
\text { Bypass surgery } \\
\text { Aorta and valve } \\
\text { replacement } \\
\text { Bentall procedure } \\
\text { Combined surgery }\end{array}$ & $\begin{array}{l}51 \\
15 \\
\\
24 \\
17\end{array}$ \\
\hline $\begin{array}{l}\text { Pes } \\
\text { No }\end{array}$ & $\begin{array}{l}34.58 \% \\
66.42 \%\end{array}$ \\
\hline
\end{tabular}

Table 1 Clinical findings in the study cohort

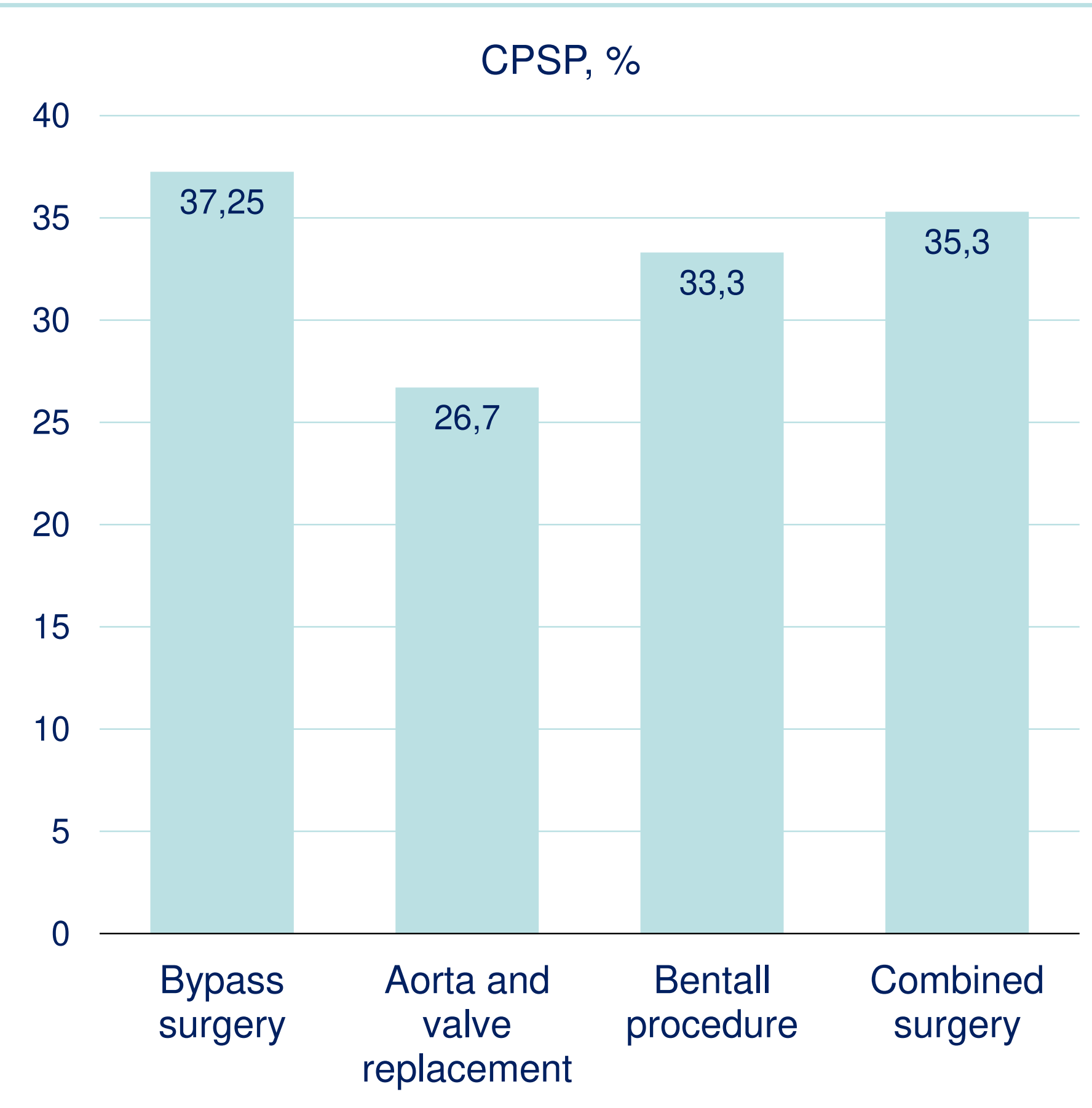

Figure 1 Prevalence of chronic pain in different surgery types

\section{References:}

1. Zagorulko O. Clin.\&Exp. Surg. 2016;3:20-27.

2. Belov Yu. Rus J Pain 2017;1(52):67-68.

3. Belov Yu. J Anest Reanimatol 2017;4:305-309.

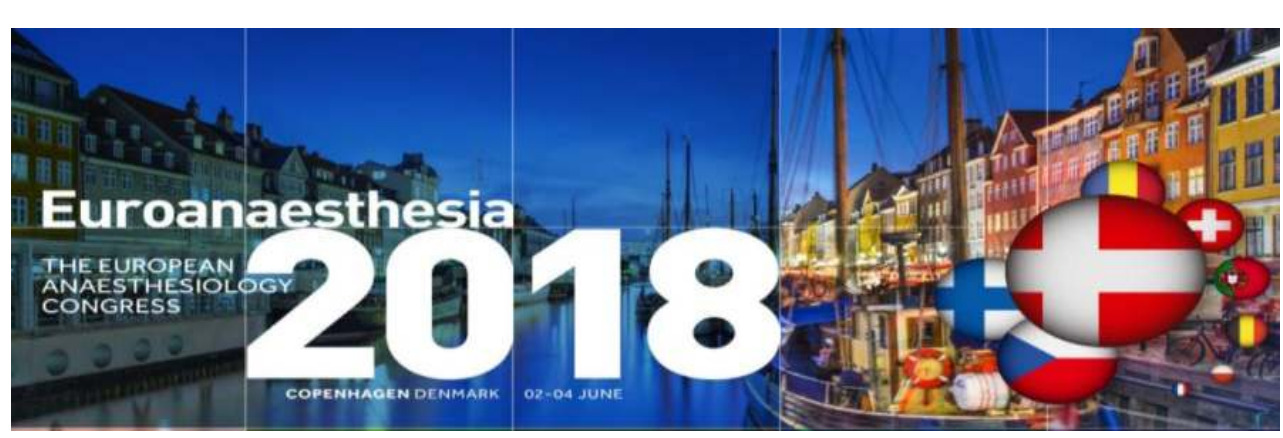

